\title{
'EDUCATIONAL' TECHNOLOGY FOR YOUNG LEARNERS: FINDING PEDAGOGICAL VALUE IN AN EMERGING INDUSTRY
}

\author{
Nicholas Cooper \\ Language Arts Teacher at Sekolah Bogor Raya \\ nicholas_k@Sekolahbogorraya.com
}

\begin{abstract}
The educational technology industry ('Ed-Tech') has rapidly risen to incredible prominence in classrooms all over the world. At the annual conference of EdTechXEurope, it was predicted that by 2020 the annual market will be around $\$ 259$ billion. Furthermore, of all of the world's regions, Asia is currently experiencing the fastest growth in investment into the sector (Scott and Loupa, 2016). Navigating this industry will become one of the greatest challenges facing educators in Indonesia. As teachers and schools continue to embrace technology, a growing concern has arisen about the pedagogical validity of this technology and whether extensive research could ever hope to keep up with its development. According to Apple, there are currently more than 80,000 Apps which fall under the umbrella of 'education' but despite a plethora of Apps currently available for young children in the iTunes Store, there has been limited systematic analysis of educational Apps and those designed specifically for young children (Goodwin, 2012). The future is arriving quickly for technological integration and the advent of technology in education has ushered in changes unparalleled in the history of learning. In order for educators to be able to confidently invest into an App, program or device, the garnering of necessary information is a sequence that cannot lightly be omitted. This paper and subsequent presentation will look into some of the incredible teaching possibilities available to teachers, schools and parents across Indonesia using the latest technology to engage young learners. Additionally, the study will illustrate some of the key concerns regarding 'EdTech' and will examine how technology teams within the school alongside discussions with online teaching communities could become integral drivers in guiding the education sector towards effective educational technology.

Key Words: Technology, Digital, App, iPad, Education, Teacher, Young Learners, Elementary School, Indonesia, Internet, Digital Natives
\end{abstract}

\section{INTRODUCTION:}

Educational technology is estimated to become a huge multi-billion dollar industry worth as much as 259 billion dollars by 2020 (Scott and Loupa, 2016). There has never been as much choice for educators and this can be a daunting prospect for many. The basic concept of the classroom, of an educator's role, and of how children learn best is the subject of debate and reimagining. The drastic changes necessary to keep pace with technology in the 21 st century "can seem intimidating and threatening" to some (Bitner and Bitner, 2002). Worries vary from a practicality standpoint to pedagogical debate of the validity of the research and subsequent claims regarding digital resources. Many educators in Indonesia admit to feeling uncomfortable with some technology and many others lament a lack of training or academic research. This paper aims to ease concerns of educators by providing clear direction and advice to consider as 
an individual and as a collective before advocating a technological initiative in the school. Discussion on this emerging market is ongoing and worldwide but for the purposes of this paper, the context will be in terms of Indonesia's relationship with technology and all that is proposed in the method section of this paper is available and inexpensive for elementary schools that are already equipped with projectors and have access to internet. Much of the paper and the research undertaken focuses upon iPads in particular as a device for young learners, although recent advances in accessibility means that many of the 'Apps' discussed are not exclusive to Apple and most of the programs advocated are available through different devices.

Despite hesitancy from some teachers, students are often reported to be positive about the idea of further use of technology in the classroom and see it as "essential for 21st century education" (Clark and Luckin, 2013). In fact, studies suggest that students with specific areas of need in an age group are often the ones reported to be the most positive (Aronin and Floyd, 2013). As Reid and Ostaschewski noted, a trial to replace the traditional methods of aiding a student with special needs in the classroom, found that "inexpensive Apps were thousands of dollars less expensive, and more readily customizable for this student" (Reid and Ostaschewski, 2011). In addition to the positivity reported from students, much of the evidence collected from parents is mainly encouraging too. In a study in 2013, the parents involved gave feedback which identified "increased engagement and interest in learning, gains in knowledge and technology skills", alongside the added benefits for parents in seeing "more time spent on homework" (Clark and Luckin, 2013). With many students and parents enthused by the prospect, the logical next step for education is for teachers to lead and champion the technology available. With the correct research into learning opportunities and with consistent teacher development programmes, technology could transform the classroom for young learners. There has already been a considerably "rapid uptake" of iPads, 'Post-PC' tablet devices in education (Clark and Luckin, 2013). Now however is the time for educators to seriously contemplate how to effectively make best use of these digital opportunities in the classroom.

\section{LITERATURE REVIEW:}

Literature regarding the digital revolution of education has been charged with the difficult if not impossible task of keeping up with a rapidly developing market. Research papers on studies using iPads that are less than a decade old allude to technological difficulties that have already been solved for the most part. Some papers propose solutions that have already been disbanded by the technology company referenced or those solutions have been so heavily updated by the company that fresh research is necessary. Likely as a response to the market seemingly spiralling out of the grasp of academic research, many critics warn that many of the claims from schools, teachers and technology companies are unsubstantiated. As Hu states: "There is very little traditional evidence that children learn more, faster or better by using these machines" (Hu, 2012). The possibilities for integrating technology into the classroom at present and certainly in the future are endless. However, as Clark and Luckin question in 2013: "Enormous investment is being made, but do we have the evidence to support this show of faith?" (Clark and Luckin, 2013). For example, a study such as Gasperini in 2011, which is commonly referenced by academics, noted that "students were more immersed in their reading and creative activities" (Gasparini, 2011). Yet how much weight these observations hold is really a matter for debate. Many of the conclusions built by proponents of educational technology are based upon subjective observations leading some to state that iPads (or similar) "might be good for learning, but we just don't have the evidence" (Subramanian, 2012). As such, whilst using digital 
technology in the classroom may seem appealing and the urge to try to immediately find a solution might feel pressing, caution is necessary. As Woo and Reeves state in conclusion to the premise that educational technology is good for the students: "More research is needed before this conjecture is validated" (Woo and Reeves, 2007).

In reality however, the traditional method of collecting quality and quantifiable evidence may never be able to keep pace with the accelerating speed and increasing variety of the educational technology market. When building a strategy for using digital resources in the classroom, this paper proposes adopting a more pragmatic and heuristic approach in regard to research. As Woo and Reeves noted: "Design guidelines for interaction in online learning are more akin to heuristics than to research-based principles" (Woo and Reeves, 2007). A heuristic approach would see educators problem-solve by researching specific Apps (or similar) that might fulfill the exact needs and context of the school. Once an idea has been decided upon, a period of adjustment should be expected and accounted for. Likely, this will necessitate constant communication between staff in order to finetune the technology to best serve the staff and students. Of course, it is necessary to be cautious when implementing technology and diligent in collecting relevant research. However, a air of pragmatism should be employed as it is unlikely that the literature on 'Ed-Tech' will provide a fully comprehensive answer to every educational technology question. There is too much variety and too many options for a text to ever fully suggest the best individual App or similar for school use. The noteworthy discussion topic to be taken from the literature and into meetings however, is that not all digital resources were created equally. For whilst, students of the 'Net Generation' simply cannot imagine their life without the internet, not every Web-based learning environment has an influence of increased learning (Woo and Reeves, 2007).

The research considered for this paper when taken overall acknowledges a shortage in traditional substantive findings and joins the academic stance of advocating for more research to be carried out worldwide. However, the positivity for programs that have been carried out successfully is undeniable. Teachers who have adapted to the digital possibilities available are often delighted with the results. As the teacher in the study by Gasperini in 2011 stated: "This is actually simplifying matters. [Learning] is immediate" (Gasparini, 2011). It is key for schools to have open discussion with staff members about digital resources and which areas of pedagogy could be improved by incorporating educational-technology into the curriculum. Guidelines for that discussion along with potential outcomes of Apps/resources that the paper advocates are below in the method section of this paper.

\section{Opportunities for Technology in the Classroom}

\section{METHOD:}

Using technology in the classroom opens the door for many teaching opportunities. However, schools cannot hope to simply state that the wish is to embrace educational technology and then hope the mantle is taken up by technologically savvy teachers who promote the right approaches. Educators must help each other navigate this potentially volatile and confusing market and must "give concrete steps in how to make these changes" (Guskey, 2002). The following is my own personal opinion and the advice I would give to any novice struggling with the wealth of options technology has brought into the field of education. The first and most important step is to decide how to proceed as a team. Too many elementary schools in Indonesia appear to introduce digital 
resources without proper collaboration amongst staff. This leads to over-repetition or inconsistency during the classes and it is important to strike a fine balance as a school. As a second recommendation, there is such an abundance of options that the onus should be on tailoring the App or similar to the school, rather than the other way around. Devising a list of conditions the digital resource should meet before separating in order to do personal research is a good way to begin. Once ideas are shared and educators are predicting the potential obstacles, it will become apparent that there are many opportunities but some are a better fit for the school than others. Here is an example list with headings devised for how technology can help in the classroom along with some examples used throughout the school I am employed currently.

\section{Collaboration - Edmodo, Google Sheets, Google Docs, Spiral}

Exploration - Virtual reality programs, Google cardboard, Google expedition, specific websites Classroom Management - Class Dojo

Differentiated Learning - MobyMax, ReadTheory, Khan Academy

Presenting in Class (Teachers and Students) - Prezi, Powtoons, Storykit, Puppetpals, Kahoot, Videos (in particular, using channels like 'Flocabulary')

Organisation - Google Drive, Dropbox, Momentum, Evernote

\section{FINDINGS AND DISCUSSION:}

Many critics appear to promote the view alluded to in the method above of personalising the technology to fit the needs of the school, such as Aronin and Floyd: "One of the keys to success is to brainstorm ways to introduce an App and discuss what skills are necessary for the students to successfully navigate and interact with the iPad" (Aronin and Floyd, 2013). Technology allows for differentiation and customization. Such advances mean that "schools can no longer push students together by age group and shove information at them, hoping they all learn at the same pace" (Khan, 2012). Khan, the founder of Khan Academy, created an online school allowing children and adults to learn at their own pace. The program is free online and states on the website that it will remain free always. The method of studying at your own personal level of ability rather than conforming to the class standard which is sometimes too difficult or easy for a student can have a positive effort. Students who have learning difficulties and struggle to keep up with the normative pace of lessons can benefit the most. As was noted in a study with a child under the pseudonym of "Josh": "In a six-week time period the student with ADHD gained a year's worth of reading improvement" (McClanahan, Williams, Kennedy, and Tate, 2012). The final consideration when discussing the method of introducing a new technology to the classroom is that the students should get to use the tools rather than being presented to all the time. It might be easy to dismiss the capabilities of the students, especially when they are young, and think that they will struggle to understand how to use the technology and that they are too small to use a program independently. However, it is important to remember that they are a new generation who have grown up immersed in technology. Young children are technologically literate and use technology as if they are speaking a language learnt. Conversely, teachers may struggle to initially understand how to use a resource in the classroom. However, such difficulties should not be automatically attributed as a commonality the students will experience. Teachers are often seen as digital immigrants to this new language, as opposed to the students who are digital natives (Palfrey and Gasser, 2013). As such, students need and crave technology. They are a net-centric generation who value their ability to use the Internet and should have the opportunity to create their own learning path, by using different forms of interactive, social, and self-publishing media tools (Baird and Fisher, 2005). It seems clear that schooling cannot 
stagnate in the face of the technological challenge. School cannot remain as it is today, it has to confront the Net-culture. (Arnesen, Elstad, and Vavik, 2016)

\section{CONCERNS FOR EDUCATIONAL TECHNOLOGY:}

Outside of the concerns for whether the academic research in the field of educational technology is enough or keeping pace, as discussed in the literature review, there are other pressing worries. The ones introduced below can be categorised into two sections: The first being pedagogical and looks into potential long term social implications. The second being financial and looks at the practical constraints facing schools and students. It could be said that while school-based learning needs to capitalize on the current generation's digital strengths, it also has to compensate that generation for what it lacks: The acquisition of disciplined knowledge and scientific thinking skills (Arnesen et al., 2016). There are some who believe that many Apps, web-based learning programs or similar are not teaching disciplined knowledge and thinking skills. As a 2013 study deduced: "There may be reasonable grounds for probing the extent to which some iPad drill and skill games are too simple and not adapted for education" (Clark and Luckin, 2013). Additionally, these technologies may limit learner interactions and are overreliant on self-instructional text (Hirumi and Bermudez, 1996 , Woo and Reeves, 2007, Clark and Luckin, 2013). Furthermore, there is a growing movement of those unconvinced that is healthy to encourage children who are 'digital natives' to continue using technology with such frequency. There is plenty to suggest that children will likely use technology outside of school anyway. It might indeed be true that "a young generation of tablet-carrying, smartphoneobsessed students might benefit from less exposure to gadgets, not more" (Harlan, 2012). Although it should be noted that complete dismissal of technology and the declaration that it has no place in the classroom is starting to grow fainter and fainter among educators as the years roll on. Nevertheless, it seems apparent that schools trying to make use of a wealth of digital resources available should have a clear rationale for adopting this technology first (Clark and Luckin, 2013).

The other main area of concern is financial. Firstly, there is the school consideration in regards to investing into a product and running it successfully. Schools must consider factors that are in addition to an initial investment outlay. There are the recurring costs of running the technology in the school and keeping a connection capable of sustaining multiple devices without lag. Smart technology-based products are not only expensive to purchase for every student, they also are dependent on high bandwidth and may not have a long life-span (Shim, Dekleva, and Madison, 2011). The temptation for schools instead is to adapt policies where the parent is responsible for funding and updating the devices like the 'Bring Your Own Device' plan. Unfortunately however, 'Bring Your Own Device' as a proposal brings with it "a raft of technical and management issues and associated resource costs". Parents also express concern about being pressured into further expense for updating the devices (Heinrich, 2012). Other parent-funded initiatives such as parents being asked to pay $£ 16$ a month over three years for their child to use an insured iPad (replaced with the latest model when available) is a difficult ask. These schemes may not be the most economically sound investment and pushing parents to pay to support it can be seen as akin to "bullying parents" (Clark and Luckin, 2013). A final concern is the cost of the Apps or similar themselves. Shopping around and being savvy when considering options will save schools money but on a larger scale there is undoubtedly an uncomfortable relationship currently being built worldwide between education and consumerism / capitalism. Teachers and parents need to be careful of Apps which appear to be free but actually have in-App purchases 
which mask the cost and encourage the adult (or child!) to pay far more than intended for something which is advertising itself as an tool to help children. Furthermore, as Gasparini observed in a study, some of the free Apps being used in the class began to show inappropriate advertisements at the five week mark (Gasparini, 2011). As a question worth considering, though admittedly with many, many exceptions: If there is no price for the App or program, am I really the customer who deserves a service or is that the advertisers? As a teacher, there are a few strategies to consider in light of this which will be discussed in the conclusion below.

\section{CONCLUSION AND SUGGESTION}

This paper concludes with a consolidation of the discussions considered. It can be said with relative certainty that educational technology is only to extend in influence in the future. This future will be viewed differently depending on the observer. As such, and in order to maintain a balance of opinions, educators in Indonesia should discuss options openly and regularly. Although, with such a wealth of opportunity available, schools in Indonesia should look to incorporate at least some digital resources into the classroom regardless of budget. There are many incredible options available currently but perhaps not all of them have been appropriately researched by independent education academics. To avoid gimmicks and inappropriate resources, educators ought to share ideas with both their immediate colleagues and with larger online teaching communities as a means of navigating this emerging market. Succeeding in this will require "relevant stakeholders take sufficient time not only to understand the key features of available devices, but, more importantly, to identify whether and how the various devices might 'best fit' the needs of their schools and the wider 'school community" (Clark and Luckin, 2013). As considered in the method section, it is wise to discuss the context and identify the needs of the students/school before actually beginning the research to find an appropriate digital resource. This should hopefully stop educators from becoming too enamoured with an impractical idea that could never work in the school. Once ideas have been collected as a group, Reid and Ostaszewski for example recommended taking the sufficient time to pitch ideas to a technology team or the board of directors, as was the case in the study in 2011: "Interested teachers were required to describe in detail how they planned to use the iPads to further student learning and demonstrate the infrastructure of support in place in the school" (Reid and Ostaschewski, 2011). These steps can help educators pool knowledge, share excitement, acknowledge concerns and discuss how to avoid an idea failing. Nevertheless and as a final point, in spite of all best efforts, this is not a guarantee of success and there is likely to be a period of adapting the technology to best fit the purpose. There is no need to panic during this period, especially if it has already been prepared for, as teachers and students will naturally need time to adapt and take ownership for a resource and express that in their own creative ways. Thankfully, there is little doubt that the students will be able to keep up with the changes long term, the concern appears to be focussed around the teachers / 'the digital immigrants'. It is our job as educators to take responsibility for developing the curriculum to keep up with the young children's digital capabilities, to ask for further training when appropriate and to allow the students in subsequent years of elementary school to lead the questioning of: "How far can educational technology take us?" 


\section{REFERENCES}

Arnesen, Elstad, Vavik. (2016). Educational Technology and Polycontextual Bridging. Rotterdam: Sense Publishers

Aronin, S., and Floyd, K. (2013). 'Using an iPad in inclusive preschool classrooms to introduce STEM concepts'. In: Teaching Exceptional Children Mar/April 2013.

Bitner, N., and Bitner, J. (2002). 'Integrating technology into the classroom: Eight keys to success. In: Journal of Technology and Teacher Education. 10(1) pp.95-100

Berson, I., Berson, M., and Manfra, M. (2012). 'Touch, type, and transform: iPads in the social studies classroom. Social Education. 76(2)

Clark, W., and Luckin, R. (2013). What the research says: iPads in the Classroom. London: Institute of Education, University of London

Gasparini, A. (2011). Children's journey with iPads in the classroom. Retrieved from https://www.researchgate.net/publication/261610768 [Assessed 20 March 2017]

Goodwin and Highfield. (2012). 'iTouch and iLearn: An examination of educational apps'. Conference for Early Education and Technology for Children. Macquarie University, Sydney, 2012

Guskey, T. R. (2012). 'Professional development and teacher change'. In: Teachers and Teaching: Theory and Practice. 8(3), pp.381-391

Harlon, C. (2012). 'In South Korean classrooms, digital textbook revolution meets some resistance.' In: The Washington Post. 24 March 2012. Retrieved from: https://articles. washingtonpost.com/2012-03-24/world/35450448_1_textbooks-digital-program-digitaleducation. [Assessed 4 April 2017]

Heinrich, P., 'The iPad as a Tool for Education.' In: NAACE and 9ine Consulting.

Hirumi, A., \& Bermudez, A. (1996). Interactivity, distance education, and instructional system design converge on the information superhighway. In: Journal of Research on Computing in Education. 29 (1-16)

Hu, W. (2012). 'Math that moves: School embrace the iPad”. The New York Times. 4 Jan 2011. Retrieved from http://www.nytimes.com/2011/01/05/education/05tablets.html [Assessed 18 March 2017]

Khan, S. (2012). 'The one world schoolhouse'. In: Education Reimagined. 12

McClanahan, B., Williams, K., Kennedy, E., and Tate, S. (2012). 'A breakthrough for Josh: How use of an iPad facilitated reading improvement'. TechTrends, 56(3), 20-28.

Palfrey, J., and Gasser, U. (2013). Born digital: Understanding the first generation of digital naties. New York, NY: Basic Books.

Scott and Loupa. (2016). 'Global Report Predicts EdTech Spend to Reach $\$ 252$ bn by 2020'. MarketWatch. May 25 2016. Retrieved from http://www.marketwatch.com/story/globalreport-predicts-edtech-spend-to-reach-252bn-by-2020-2016-05-25-4203228 [Assessed 17 Jan 2017]

Shim, J., Dekleva, S., and Madison, J,. (2011). 'Twitter, Google, iPhone/iPad, and Facebook (TGIF) and Smart Technology Environments: How Well Do Educators Communicate with Students via TGIF?' In: Communications of the Association for Information Systems. Volume 29, (35)

Subramanian, C. (2012). 'New study finds iPads in the classroom boosts test scores.' TIME Tech. 22 Feb 2012. Retrieved from http://techland.time.com/2012/02/22/new-study-findsiPads-in-the-classroom-boost-test-scores/ [Assessed 1 April 2017]

Reid, D. \& Ostashewski, N. (2011). iPads in the Classroom - New Technologies, Old Issues: Are they worth the effort?. In T. Bastiaens \& M. Ebner (Eds.), Proceedings of World 
Conference on Educational Multimedia, Hypermedia and Telecommunications 2011 (pp. 1689-1694). Chesapeake, VA: AACE.

Woo, Y., and Reeves, T. (2007). 'Meaningful interaction in web-based learning: A social constructivist interpretation. In: Internet and Higher Education. 10 (15-25) 